\title{
Valorization the waste of the wood industry (sawdust) and their use as adsorbent material: physicochemical characterization and modeling of optimization sorption using statistical approach
}

\author{
Asmaa SALAMAT ${ }^{1}$, Ayoub AINANE ${ }^{1}$, Laila DAHBI ${ }^{1}$, Fatima KHAMMOUR ${ }^{1}$, \\ Meriem ADIB ${ }^{1}$, Abdelkbir KENZ ${ }^{1}$, Mohammed TALBI ${ }^{1}$, El Hassan ABBA ${ }^{2}$, \\ M'hamed ELKOUALI', Tarik AINANE ${ }^{1,2} *$ \\ ${ }^{1}$ Laboratory of Analytical Chemistry and Physical Chemistry of Materials, Faculty of Sciences Ben Msik, University of Hassan \\ II, BP 7955 Casablanca 20660, Morocco. \\ ${ }^{2}$ Superior School of Technology - Khenifra (EST-Khenifra), University of Moulay Ismail,
} PB 170, Khenifra 54000 Morocco.

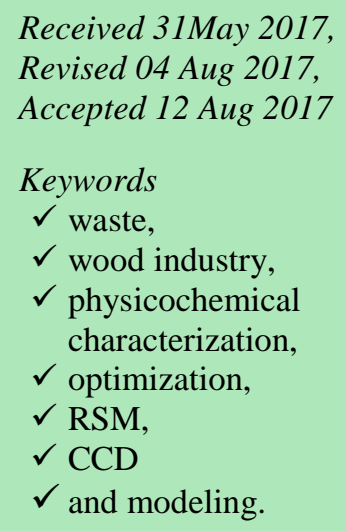

Received 31May 2017

Revised 04 Aug 2017,

Accepted 12 Aug 2017

$$
\begin{aligned}
& \text { Keywords } \\
& \checkmark \text { waste, } \\
& \checkmark \text { wood industry, } \\
& \checkmark \text { physicochemical } \\
& \quad \text { characterization, } \\
& \checkmark \text { optimization, } \\
& \checkmark \text { RSM, } \\
& \checkmark \text { CCD } \\
& \checkmark \text { and modeling. }
\end{aligned}
$$

$\left({ }^{*}\right)$ ainane@gmail.com ; Phone: +212535384 591;

\begin{abstract}
The present work reports on simple and effective ecofriendly approach for the valorization of waste of the wood industry in the environmental application as adsorbent biomaterials. The biomaterial was characterized using various instrumental techniques including scanning electron microscope coupled at energy dispersive spectroscopy (SEM/EDS) and Fourier transformed infrared spectroscopy (FTIR). In the other hand, other study is about optimization of sorption of Methylene Blue dye (MB) from aqueous solution onto the biomaterial prepared from waste of the wood industry using Response Surface Methodology (RSM). Effect of process parameters such as dosage of biomaterial, initial dye concentration, stirring speed, size of grains of adsorbent, and their interaction on the sorption were studied by using full factorial Central Composite Design (CCD).
\end{abstract}

\section{Introduction}

The effluents coming from different industries such as textile, leather, paint, pulp and paper, ceramic, pottery ... that use synthetic dyes to color their products, may lead to water pollution if they are not treated properly before their discharge to the environment [1-10]. Methylene Blue (MB), a common dye used for dying cotton, silk and wood, has adverse effect on human health such as breathing problem, eye burns, diarrhea, vomiting and gastritis [11-12]. Conventional waste water treatment methods for removing dyes especially methylene blue include physicochemical, chemical and biological methods, such as coagulation and flocculation, ozonation, electrochemical techniques, fungal decolorization and others techniques. [13-16]. But these processes are not always effective and economic where the solute concentrations are very low. Besides, most of the dyes undergo very slow biodegradation. Actually, the elimination by sorption technique has been proven to be an effective and attractive process for the treatment of dye-containing waste water [17]. In recent years, adsorption has been strongly recommended as an economically viable sustainable technology for the treatment of waste water streams [18]. The importance and usefulness of adsorption in wastewater treatment is well established [19]. Adsorption in environmental engineering is now in the focus and consideration of all nations, owing to its low initial cost, simplicity of design, ease of operation, insensitivity to toxic substances and complete removal of pollutants even from dilute solutions [20-21].

The focus of this research is to evaluate the adsorption potential of waste of the wood industry for Methylene Blue. MB was chosen in this study because of its known strong adsorption onto solids and it often serves as a model compound for removing organic contaminants. Thus, an experimental design methodology with four 
factor interaction was implemented in order to optimizing the conditions for the process sorption of this adsorbent biomaterial.

This manuscript is a continuation of the work done by L. Dahbi et al. [22], From which they made a preliminary contribution to the study of the fixing of Methylene Blue (MB) on sawdust of beech, Moreover, they have demonstrated the dependence of the efficiency of this adsorbent on various operating parameters (initial $\mathrm{pH}$, initial concentration of the adsorbate, agitation speed, adsorbent mass). Theoretically, adsorption isotherms of Methylene Blue (MB) by sawdust from beech wood have been validated by Langmuir, Freundlich, Temkin and Elovich models. The adsorption process was confirmed by the Langmuir model, and the application of the kinetic models based on the second Fick's law allowed us to estimate, for different initial concentrations in Methylene Blue, the parameters related to the transfer resistances of external and internal material.

\section{Material and Methods}

\subsection{Preparation of sawdust biomaterial}

The waste wood (sawdust) was collected from the waste industry (Ain Sbaa, Casablanca, Morocco). The collected materials were washed several times with boiled water and finally with distilled water to remove any adhering dirt. The washed material was then dried in the oven at $60^{\circ} \mathrm{C}$ for $72 \mathrm{~h}$. Finally, the resulting obtained was stored for further use.

\subsection{Characterization of sawdust biomaterial}

\subsubsection{SEM/EDS analysis}

Scanning Electron Microscope (SEM) JSM- 5800 LV, JEOL was used to determine the shape of sawdust biomaterial. Elemental composition of the sample was analyzed with energy dispersive analysis of X-ray spectroscopy (EDS) coupled to the Scanning Electron Microscope.

\subsubsection{FTIR analysis}

Fourier transformed infrared (FTIR) spectrum of the sample was recorded by Fourier transform infrared spectrophotometer (VERTEX 70). The FTIR spectrum ranged from 4000 to $400 \mathrm{~cm}^{-1}$ at a resolution of $4 \mathrm{~cm}^{-1}$. For FTIR study, $2 \mathrm{mg}$ of finely ground sample was mixed well with approximately $40 \mathrm{mg}$ of $\mathrm{KBr}$ (MERCK) for the preparation of transparent pellets, from which functional groups were determined.

\subsection{Modeling and optimization sorption}

\subsubsection{Preparation of dye solution}

Methylene Blue (MB) is a cationic dye (Figure 1) with molecular formula $\mathrm{C}_{16} \mathrm{H}_{18} \mathrm{~N}_{3} \mathrm{SCl}$, molar weight of $319.85 \mathrm{~g} / \mathrm{mol}$ and wave length of $\lambda_{\max }=664 \mathrm{~nm}$ [23-24]. The stock solutions of MB were prepared in distilled water. All working solutions were prepared by diluting the stock solution with distilled water to the needed concentration. Fresh dilutions were used for each adsorption study.

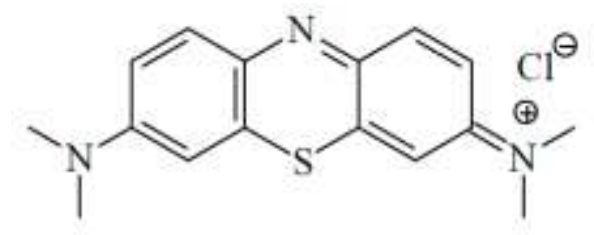

Figure 1: Chemical structure of methylene blue.

\subsubsection{Tests of sorption}

The adsorption tests were carried out in a static reactor under the same operating conditions. Known mass of the adsorbent is introduced into a solution containing a concentration of methylene blue. The mixture is stirred at room temperature for a sufficient time of equilibrium ( 2 hours), and then the experiment's stopped for one hour to determine their residual concentrations. It's noted that all the experiments are repeated in triplicate in order to have an average and a standard deviation from the results. The yield removal of dye was calculated as follows:

$$
\operatorname{Yield}(\%)=\left(\frac{C_{0}-C_{e}}{C_{0}}\right) \times 100
$$

Where $\mathrm{C}_{0}$ and $\mathrm{C}_{\mathrm{e}}(\mathrm{mg} / \mathrm{L})$ are the liquid phase concentrations of $\mathrm{MB}$ at initial and equilibrium, respectively. 
In the other hand, all experiments were performed at a temperature $\left(25 \pm 2{ }^{\circ} \mathrm{C}\right)$. We first prepared the sawdust sifting for various aggregates $(63.80$ and $100 \mu \mathrm{m})$ from which we weighed the different mass $(0.1,0.2$ and $0.3 \mathrm{~g}$ / 1), then, added to stock solution of $100 \mathrm{mg} / \mathrm{l}$, we have prepared by dilution concentrations $(10,15$ and 20 $\mathrm{mg} / \mathrm{l})$. The sorptions are performed for different stirring speeds $(800,1200$ and $1600 \mathrm{rpm})$ at the equilibrium time of two hours.

\subsubsection{Design of experiments}

Response Surface Methodology is a statistical method that uses experimental data obtained from specified experimental design to model and optimize any process in which response of interest is influenced by several variables [25]. Primarily, this optimization is done by following three major steps viz., performing the statistically designed experiments, estimating the coefficients in a mathematical model and predicting the responses and examining the adequacy of the model [26]. RSM helps to enumerate the relationships between output variables called responses $(\mathrm{Y})$ and input variables called factors $\left(\mathrm{X}_{\mathrm{i}}\right)$ [27].

$$
Y=f\left(X_{1}, X_{2}, X_{3}, \ldots, X_{n}\right) \quad(2)
$$

A standard RSM design called Central Composite Design (CCD) was applied in the present work. This method is suitable for fitting a quadratic surface and it helps to optimize the effective parameters with a minimum number of experiments, as well as to analyze the interaction between the parameters [28]. Generally, the CCD consists of a $2^{\mathrm{n}}$ factorial runs with $2 \mathrm{n}$ axial runs and $\mathrm{n}_{\mathrm{c}}$ central runs [29]. The centre points are utilized to evaluate the experimental error and the reproducibility of the data. Thus, for carbonization process having three independent parameters $(\mathrm{n}=4)$, the total number of experiments required is:

$$
N=2^{n}+2 . n+n_{c}=16+(2 \times 4)+2=26 \quad(3)
$$

The experimental sequence was randomized in order to minimize the effects of uncontrolled factors [30]. The outcome of each experimental run was analyzed and the response was correlated with three input factors for carbonization of parthenium for preparation of adsorbent through an empirical second degree polynomial equation as given by the following equation:

$$
Y=\beta_{0}+\sum_{i=1}^{n} \beta_{i} X_{i}+\sum_{i=1}^{n} \beta_{i i} X_{i}^{2}+\sum_{i=1}^{n} \sum_{j=1}^{n-1} \beta_{i j} X_{i} X_{j}
$$

Where, $\mathrm{Y}$ is the predicted response (Yield of sorption in this study), $\beta_{0}$ the constant coefficient, $\beta_{\mathrm{i}}$ the linear coefficients, $\beta_{\mathrm{ij}}$ the interaction coefficients and $\beta_{\mathrm{ii}}$ the quadratic coefficient [31]. ANOVA was used to model the system represented by independent parameters and dependent output response and to optimize the system by estimating the statistical parameters. The minimum $(-1)$, intermediate $(0)$ and maximum $(+1)$ level of dosage of biomaterial, initial dye concentration, stirring speed, size of grains of adsorbent were $0.1,0.2$ and $0.3 \mathrm{~g} / \mathrm{l}, 10,20$ and $30 \mathrm{mg} / \mathrm{l}, 800,1200$ and $1600 \mathrm{rpm}$ and $60,80,100 \mu \mathrm{m}$ respectively. The statistical experimental design as specified by the software is shown in Table 1 .

\section{Results and discussion}

\subsection{Physicochemical characterization}

Sawdust (industrial waste) used in this study is derived from beech (Fagus sp.), which is a widely used wood in construction and furnishings (Figure 2). Beech is a very hard, heavy, white to reddish wood, very alterable and not very durable, but it is impregnated, dyed, painted, turned and easily bent. High quality beech is used in the manufacture of plywood. But it is also very appreciated for furniture and turnery. Poor quality wood is used for particle board and pulp.

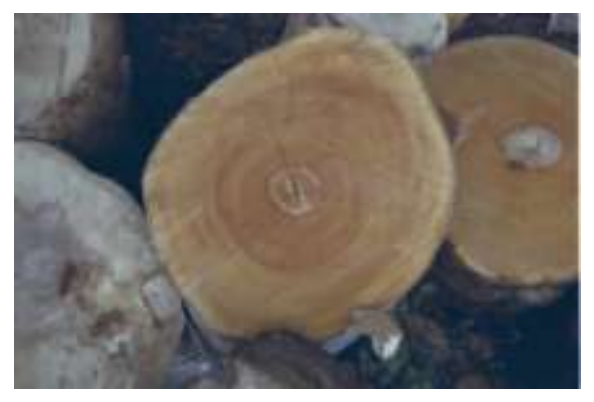

Figure 2: Beech (wood).

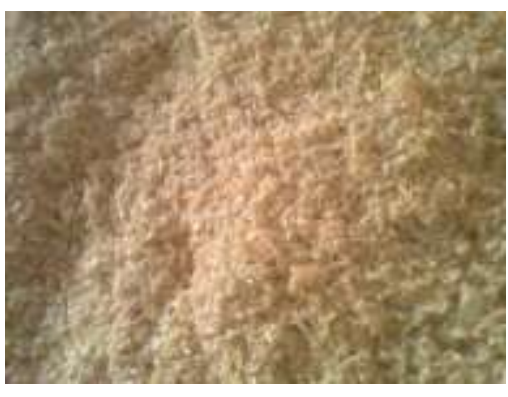

Figure 3: Wood waste from beech. 
Physico-chemical analysis of this material was carried out by scanning electron microscope (SEM) coupled at energy dispersive spectroscopy (EDS) and Fourier transformed infrared spectroscopy (FTIR).

Analysis by scanning electron microscopy is carried out on wood samples at $200 \mu \mathrm{m}$ and at $300 \mu \mathrm{m}$. The plates are shown in Figure 4. This analysis shows that this material is microporous.
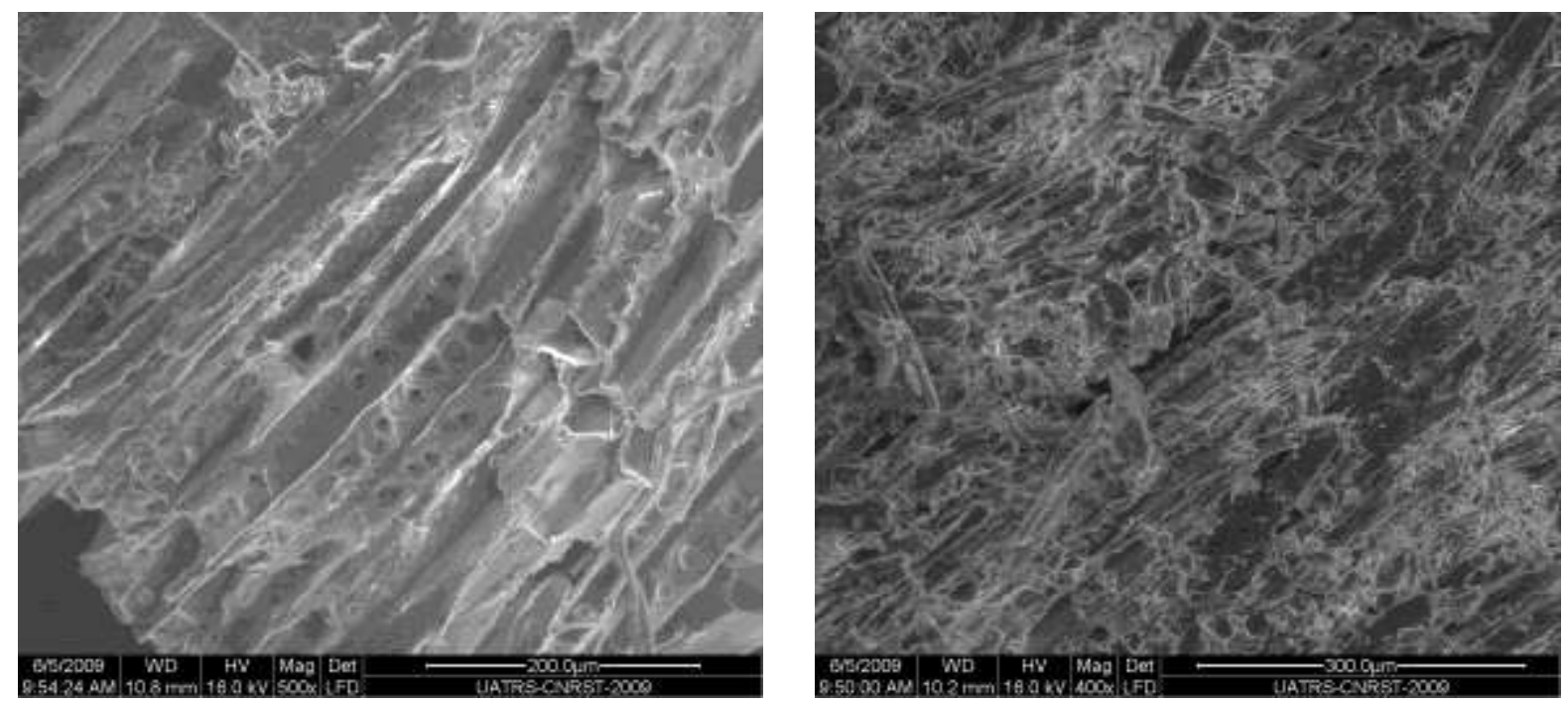

Figure 4: SEM of wood: $200 \mu \mathrm{m}$ and $300 \mu \mathrm{m}$.

As a result, the microanalysis $\mathrm{X}$ by EDS allows the qualitative and quantitative determination on the scale of the cubic micron of the chemical elements contained in very diverse materials: rocks, metal alloys, powder, etc. The detection limit is about 10-14 to 10-15 g which corresponds to a content of less than $100 \mathrm{ppm}$. This analysis allowed us to characterize a number of elements that the samples contain. These elements have been identified by their binding energy which is characteristic and listed in the spectroscopic tables. The relative contents of the various elements expressed as atomic percent are grouped in Table 1. The atomic composition as a percentage by mass determined by EDS showed that the content of carbon and oxygen is very important in the waste wood, this shows that both elements are the elementary constituents of wood, the presence of Some elements such as aluminum, chlorine, calcium and potash with variable grades, which probably originate from substances absorbed by the tree in the soil.

Table 1: Percent atomic composition determined by EDS.

\begin{tabular}{|c|c|}
\hline Composition & Percentage content (\%) \\
\hline $\mathrm{C}$ & 70.12 \\
\hline $\mathrm{O}$ & 28.68 \\
\hline $\mathrm{Al}$ & 0.22 \\
\hline $\mathrm{Si}$ & 0.39 \\
\hline $\mathrm{Cl}$ & 0.18 \\
\hline $\mathrm{K}$ & 0.17 \\
\hline $\mathrm{Ca}$ & 0.24 \\
\hline
\end{tabular}

In the other hand, FTIR makes it possible to identify the functional groups that are characteristic of the compounds. This technique does not make it possible to precisely define the structure of a molecule as complex as lignin. However, the results obtained show major differences in the main components of wood such as lignin, cellulose and hemicellulose, so thesample spectrum of wood waste is presented in Figure 5.

A broad band in the region of $3400 \mathrm{~cm}^{-1}$ represented presence of hydroxyl groups $(\mathrm{OH})$, Furthermore the valence vibration related to aromatic $\mathrm{C}-\mathrm{H}$ is shown on the spectrum. It is characterized by absorptions at the $3030 \mathrm{~cm}^{-1}$ region. The characteristic functions of the basic units of lignin are aromatic functions, carbonyls $(\mathrm{C}=$ $\mathrm{O}$ ), alcohols and ethers. Each of these functions is found in the infrared spectrum. The aromatic functions are characterized by infra-red absorption bands in the region of 1500 to $1600 \mathrm{~cm}^{-1}$, which is characteristic of the $\mathrm{C}=$ $\mathrm{C}$ vibrations of the aromatic skeleton of lignin. Thus, fundamental studies on the vibrations of benzene have shown that the valence vibration mode of the carbon-carbon bonds conjugated from the aromatic skeleton leads to the appearance of 4 bands lying between 1650 and $1450 \mathrm{~cm}^{-1}$ [32-34]. 


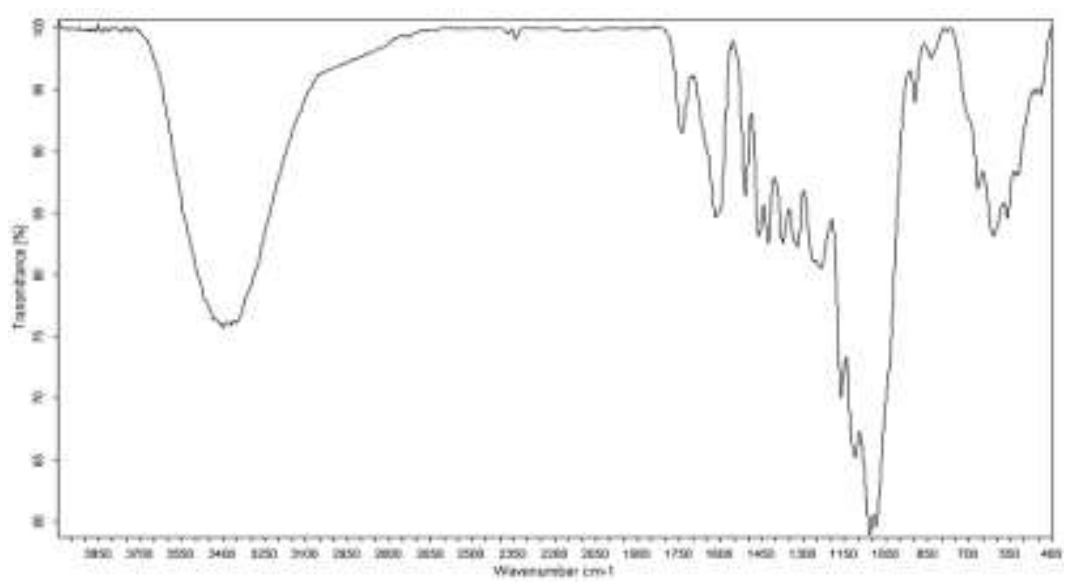

Figure 5: FTIR spectrum of sawdust (beech wood).

3.2. Modeling of optimization sorption using statistical approach

The experimental plan chosen is a composite plan centered in a cubic domain, each factor requires 3 levels, and the number of simulations is equal to 26, or the experimental design is given in Table 2. Therefore, the mathematical model associated at empirical second degree polynomial for response of correlated with four input factors given by the following equation 5 :

$$
\begin{aligned}
& Y=86.95-2.62 X_{1}+4.27 X_{2}-0.31 X_{3}-2.76 X_{4}-2.22 X_{1}^{2}-4.82 X_{2}^{2}+2.56 X_{3}^{2}+2.31 X_{4}^{2} \\
& +3.14 X_{1} X_{2}-0.29 X_{1} X_{3}-1.20 X_{2} X_{3}+1.01 X_{1} X_{4}-1.44 X_{2} X_{4}+0.12 X_{3} X_{4}
\end{aligned}
$$

\begin{tabular}{|c|c|c|c|c|c|}
\hline & $\mathrm{X} 1$ & $\mathrm{X} 2$ & $\mathrm{X3}$ & $\mathrm{X} 4$ & \\
\hline Number of trials & $\mathrm{C}(\mathrm{mg} / \mathrm{l})$ & m (g/l) & $\mathbf{G}(\mu \mathrm{m})$ & V(rpm) & $\mathrm{Y}($ yield $)$ \\
\hline 1 & 10 & 0.1 & 60 & 800 & 88.03 \\
\hline 2 & 20 & 0.1 & 60 & 800 & 76.84 \\
\hline 3 & 10 & 0.3 & 60 & 800 & 95.45 \\
\hline 4 & 20 & 0.3 & 60 & 800 & 93.98 \\
\hline 5 & 10 & 0.1 & 100 & 800 & 91.59 \\
\hline 6 & 20 & 0.1 & 100 & 800 & 75.50 \\
\hline 7 & 10 & 0.3 & 100 & 800 & 91.51 \\
\hline 8 & 20 & 0.3 & 100 & 800 & 91.94 \\
\hline 9 & 10 & 0.1 & 60 & 1600 & 82.71 \\
\hline 10 & 20 & 0.1 & 60 & 1600 & 74.03 \\
\hline 11 & 10 & 0.3 & 60 & 1600 & 83.87 \\
\hline 12 & 20 & 0.3 & 60 & 1600 & 87.27 \\
\hline 13 & 10 & 0.1 & 100 & 1600 & 85.34 \\
\hline 14 & 20 & 0.1 & 100 & 1600 & 75.93 \\
\hline 15 & 10 & 0.3 & 100 & 1600 & 81.10 \\
\hline 16 & 20 & 0.3 & 100 & 1600 & 83.61 \\
\hline 17 & 10 & 0.2 & 80 & 1200 & 86.92 \\
\hline 18 & 20 & 0.2 & 80 & 1200 & 80.29 \\
\hline 19 & 15 & 0.1 & 80 & 1200 & 71.99 \\
\hline 20 & 15 & 0.3 & 80 & 1200 & 90.02 \\
\hline 21 & 15 & 0.2 & 60 & 1200 & 88.38 \\
\hline 22 & 15 & 0.2 & 100 & 1200 & 88.38 \\
\hline 23 & 15 & 0.2 & 80 & 800 & 87.50 \\
\hline 24 & 15 & 0.2 & 80 & 1600 & 88.77 \\
\hline 25 & 15 & 0.2 & 80 & 1200 & 90.45 \\
\hline 26 & 15 & 0.2 & 80 & 1200 & 90.20 \\
\hline
\end{tabular}

Table 2: Experimental design (input and response factors). 
As a result, we have compared the calculated and simulated responses, hence for each row of the experimental design, and model computes a value for each of the responses. In addition, we calculated the differences between these responses. The results obtained are shown in Table 2. From the difference column of Table 3, we find that the response models (yield (\%)) benefit from a good descriptive quality since the percentage difference between the responses calculated and the simulated responses is low. It can also be noted that the largest values of the percentage difference are obtained $(7.53,4.03$ and 4.91) in experiments 19,20 and 21 . We will verify using statistical tests whether these experiences can be considered an atypical experience, so values of the studentized residuals as a function of the calculated response are shown in the figure 6. From this figure, it can be said that experiments 19,20 and 21 appear to be atypical.

Table 3: Calculated responses and simulated responses.

\begin{tabular}{|c|c|c|c|c|}
\hline $\begin{array}{l}\text { Number of } \\
\text { experience }\end{array}$ & $\mathbf{Y}_{\exp }(\%)$ & $\mathbf{Y}_{\text {calc }}(\%)$ & $\begin{array}{c}\text { Difference } \\
\text { Calculated responses } \\
(\%)\end{array}$ & $\begin{array}{c}\text { Difference } \\
\text { simulated responses } \\
(\%)\end{array}$ \\
\hline 1 & 88.03 & 87.54 & 0.48 & 0.56 \\
\hline 2 & 76.84 & 74.58 & 2.25 & 2.94 \\
\hline 3 & 95.45 & 95.07 & 0.37 & 0.39 \\
\hline 4 & 93.98 & 94.67 & -0.69 & 0.73 \\
\hline 5 & 91.59 & 89.65 & 1.93 & 2.12 \\
\hline 6 & 75.5 & 75.54 & -0.04 & 0.05 \\
\hline 7 & 91.51 & 92.39 & -0.88 & 0.95 \\
\hline 8 & 91.94 & 90.84 & 1.09 & 1.19 \\
\hline 9 & 82.71 & 82.65 & 0.05 & 0.07 \\
\hline 10 & 74.03 & 73.73 & 0.29 & 0.40 \\
\hline 11 & 83.87 & 84.41 & -0.54 & 0.64 \\
\hline 12 & 87.27 & 88.05 & -0.78 & 0.88 \\
\hline 13 & 85.34 & 85.23 & 0.11 & 0.13 \\
\hline 14 & 75.93 & 75.15 & 0.77 & 1.03 \\
\hline 15 & 81.1 & 82.20 & -1.10 & 1.34 \\
\hline 16 & 83.61 & 84.68 & -1.07 & 1.26 \\
\hline 17 & 86.92 & 87.34 & -0.42 & 0.48 \\
\hline 18 & 80.29 & 82.11 & -1.82 & 2.21 \\
\hline 19 & 71.99 & 77.86 & -5.87 & 7.53 \\
\hline 20 & 90.02 & 86.39 & 3.62 & 4.03 \\
\hline 21 & 88.38 & 89.82 & -1.44 & 1.00 \\
\hline 22 & 88.38 & 89.19 & -0.81 & 0.90 \\
\hline 23 & 87.50 & 92.02 & -4.52 & 4.91 \\
\hline 24 & 88.77 & 86.49 & 2.27 & 2.56 \\
\hline 25 & 90.45 & 86.94 & 3.50 & 3.88 \\
\hline 26 & 90.20 & 86.94 & 3.25 & 3.61 \\
\hline
\end{tabular}

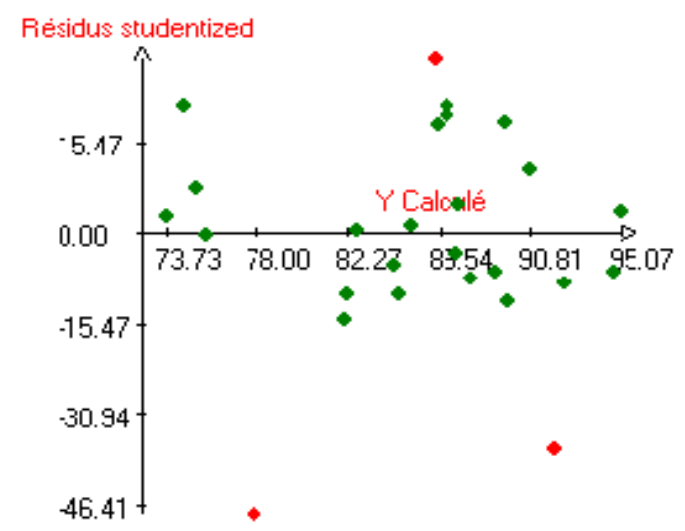

Figure 6: Normality of residues. 
Table 4 presents the variance analysis (ANOVA) of the responses presented in percentage units (\%). Results of this table, we see that the $\mathrm{Fc}$ probability value is less than $5 \%$, so we can say that the model correctly describes the variation of the test results. In addition, the determination coefficients $\mathrm{R}^{2}$ are shown in Table 5 . It can be seen that the quality of the model is not very good since the value of determination coefficients adjusted $\mathrm{R}_{\mathrm{A}}^{2}$ and predictive $\mathrm{R}_{\text {pred }}^{2}$ and are equal to 0.741 and 0.510 .

Therefore, the statistical coefficients and the estimates according to the student's law are presented in Table 6 . From this table, we find that the coefficients $b_{0}, b_{1}, b_{2}, b_{4}, b_{11}, b_{22}, b_{33}, b_{44}, b_{12}, b_{23}, b_{14}$ and $b_{24}$ have an influence on the adsorption performance.

Table 4: ANOVA results.

\begin{tabular}{|c|c|c|c|c|c|}
\hline $\begin{array}{c}\text { Source of } \\
\text { variation }\end{array}$ & Sum of squares & $\begin{array}{c}\text { Degree of } \\
\text { freedom }\end{array}$ & mean square & Fc & $\begin{array}{c}\text { Probability } \\
\text { Fc }\end{array}$ \\
\hline Regression & 918 & 14 & 65.6 & 2100 & $1.94 *$ \\
\hline Residues & 118 & 11 & 10.7 & - & - \\
\hline Validity & 118 & 10 & 11.8 & 377 & $4.13^{*}$ \\
\hline Error & 312 & 1 & 0.03 & - & - \\
\hline Total & 1036 & 25 & - & - & - \\
\hline
\end{tabular}

Table 5: Descriptive and predictive qualities of models.

\begin{tabular}{|c|c|}
\hline Standard Error of the response & 0.177 \\
\hline Determination coefficient $\mathbf{R}^{\mathbf{2}}$ & 0.886 \\
\hline Adjusted of determination coefficient $\mathbf{R}_{\mathbf{A}}^{\mathbf{2}}$ & 0.741 \\
\hline Predictive of determination coefficient $\mathbf{R}_{\text {pred }}^{\mathbf{2}}$ & 0.510 \\
\hline
\end{tabular}

Table 6: Estimates and Statistical Coefficients.

\begin{tabular}{|c|c|c|c|c|c|}
\hline Name & Coefficient & F. Inflation & $\begin{array}{c}\text { Standard } \\
\text { Deviation }\end{array}$ & $\mathbf{t}_{\cdot \text { exp. }}$ & Sig. \% \\
\hline $\mathrm{b}_{0}$ & 86.95 & - & 0.07 & 1199 & $0.51^{* *}$ \\
\hline $\mathrm{b}_{1}$ & -2.62 & 1.00 & 0.04 & -60.73 & $1.28^{*}$ \\
\hline $\mathrm{b}_{2}$ & 4.27 & 1.00 & 0.04 & 98.93 & $0.97^{* *}$ \\
\hline $\mathrm{b}_{3}$ & -0.31 & 1.00 & 0.04 & -7.26 & 8.9 \\
\hline $\mathrm{b}_{4}$ & -2.76 & 1.00 & 0.04 & -64.05 & $1.24 *$ \\
\hline $\mathrm{b}_{11}$ & -2.22 & 2.16 & 0.11 & -19.41 & $3.21^{*}$ \\
\hline $\mathrm{b}_{22}$ & -4.82 & 2.16 & 0.11 & -42.17 & $1.64 *$ \\
\hline $\mathrm{b}_{33}$ & 2.56 & 2.16 & 0.11 & 22.39 & $2.80^{*}$ \\
\hline $\mathrm{b}_{44}$ & 2.31 & 2.16 & 0.11 & 20.21 & $3.09^{*}$ \\
\hline $\mathrm{b}_{12}$ & 3.14 & 1.00 & 0.05 & 68.64 & $1.19^{*}$ \\
\hline $\mathrm{b}_{13}$ & -0.29 & 1.00 & 0.05 & -6.35 & 10.3 \\
\hline $\mathrm{b}_{23}$ & -1.20 & 1.00 & 0.05 & -26.19 & $2.43 *$ \\
\hline $\mathrm{b}_{14}$ & 1.01 & 1.00 & 0.05 & 22.08 & $2.84 *$ \\
\hline $\mathrm{b}_{24}$ & -1.44 & 1.00 & 0.05 & -31.53 & $2.07 *$ \\
\hline $\mathrm{b}_{34}$ & 0.12 & 1.00 & 0.05 & 2.53 & 24.8 \\
\hline
\end{tabular}

Finally, figures $7,8,9,10,11$ and 12 present graphical studies in two forms: response surfaces (twodimensional 2D) and iso-response curves (three-dimensional 3D). A major advantage of the design of this experiment is the ability to generate multiple graphic representations of the data. 


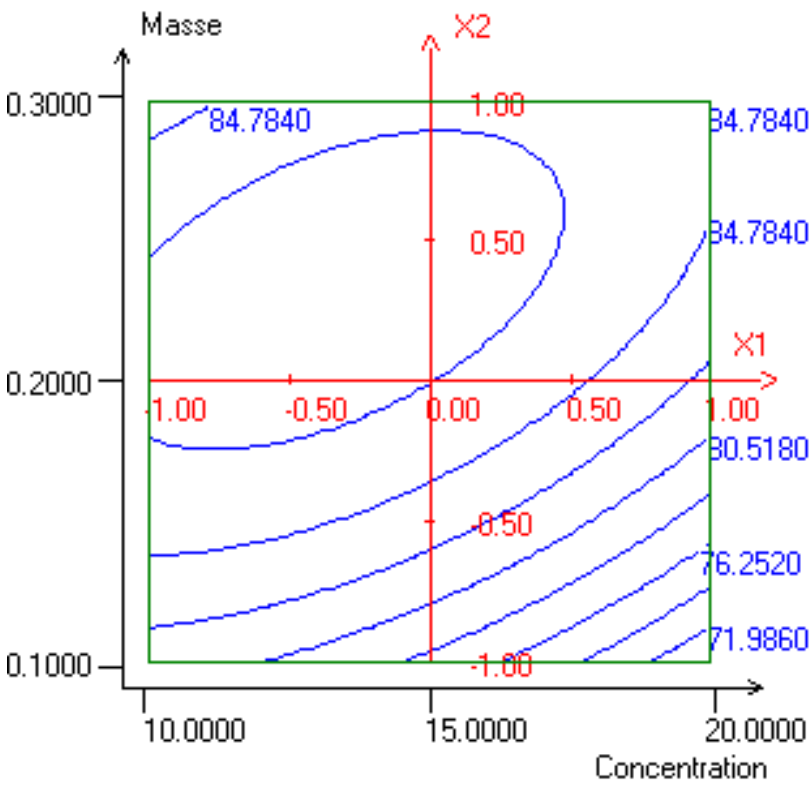

2D
Réponse

93.3160

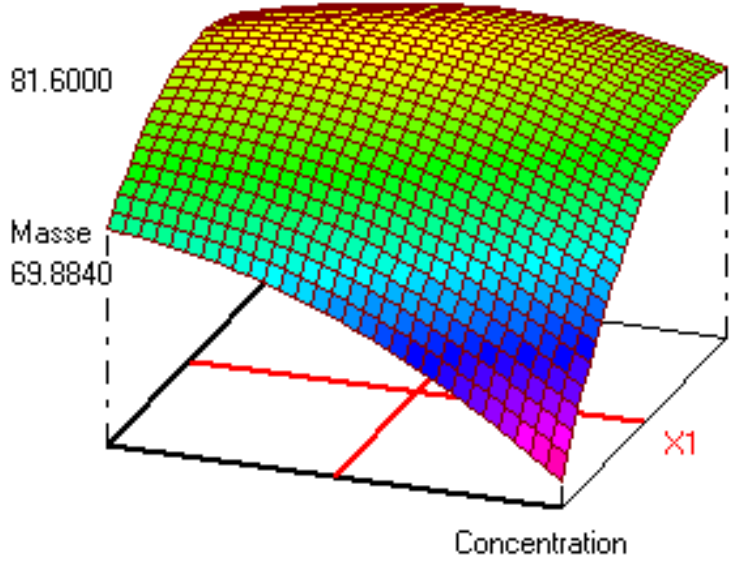

$3 \mathrm{D}$

Figure 7: Response surface in 2D and 3D. (Change in the response - Efficiency in the plan: Concentration, Mass ; Factors fixed: - Particle size $=80$ micrometer - speed $=1200 \mathrm{rpm})$

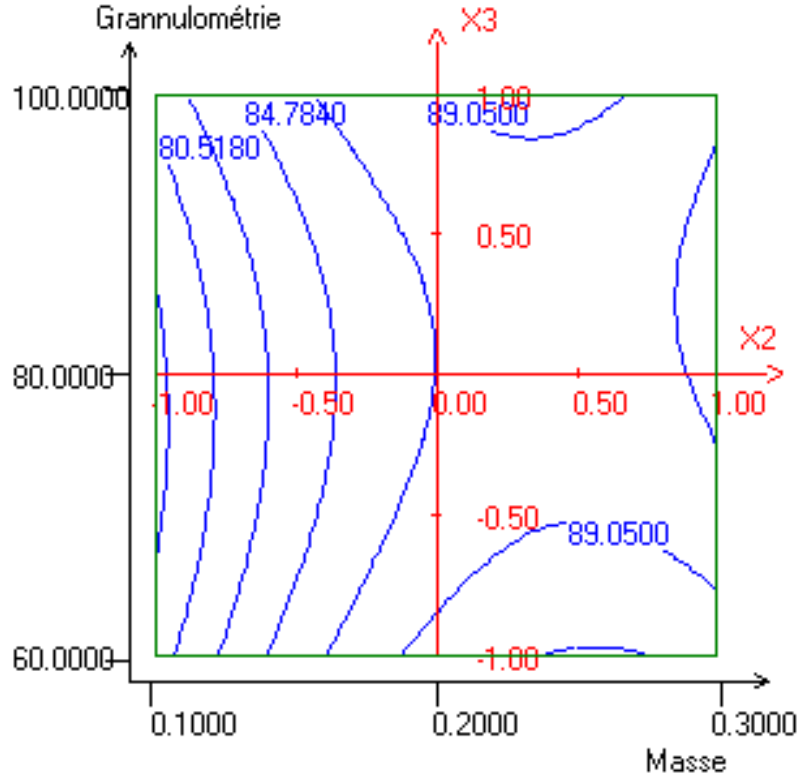

$2 \mathrm{D}$
Réponse

93.3160

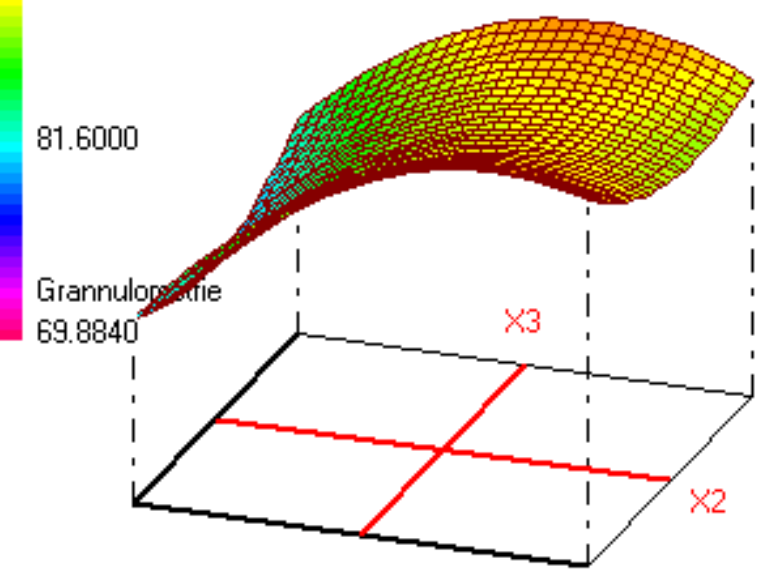

Masse

3D

Figure 8: Response surface in 2D and 3D. (Change in the response - Efficiency in the plan: Masse, Grit ; Factors fixed: Concentration $=15 \mathrm{mg} / \mathrm{l}-$ Speed $=1200 \mathrm{rpm}$ ) 


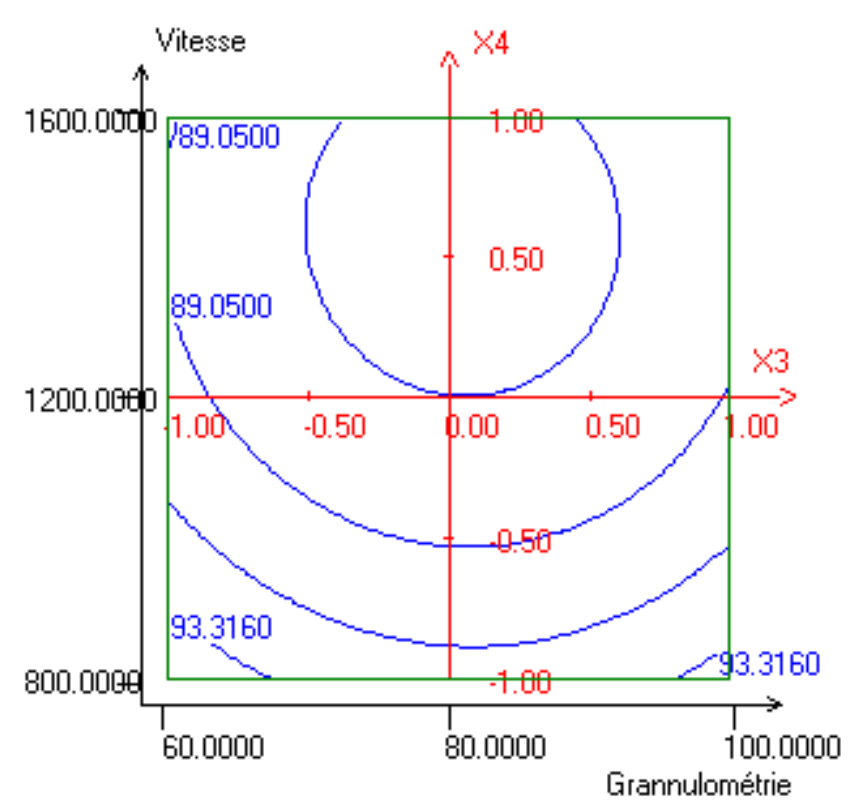

2D
Réponse

95.0080

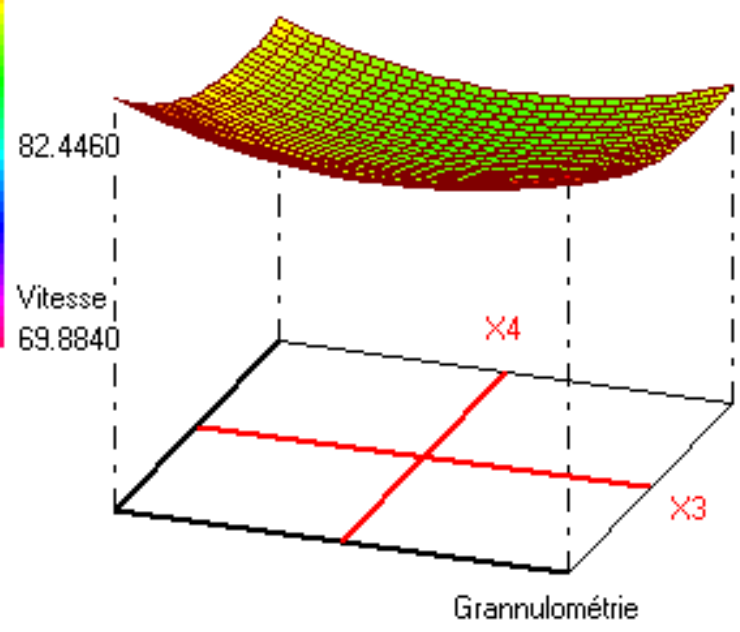

3D

Figure 9: Response surface in 2D and 3D. (Change in the response - Efficiency in the plan: Particle Size, Speed ; Factors fixed: - Concentration $=15 \mathrm{mg} / \mathrm{l}-$ Weight $=0.2 \mathrm{~g}$ )

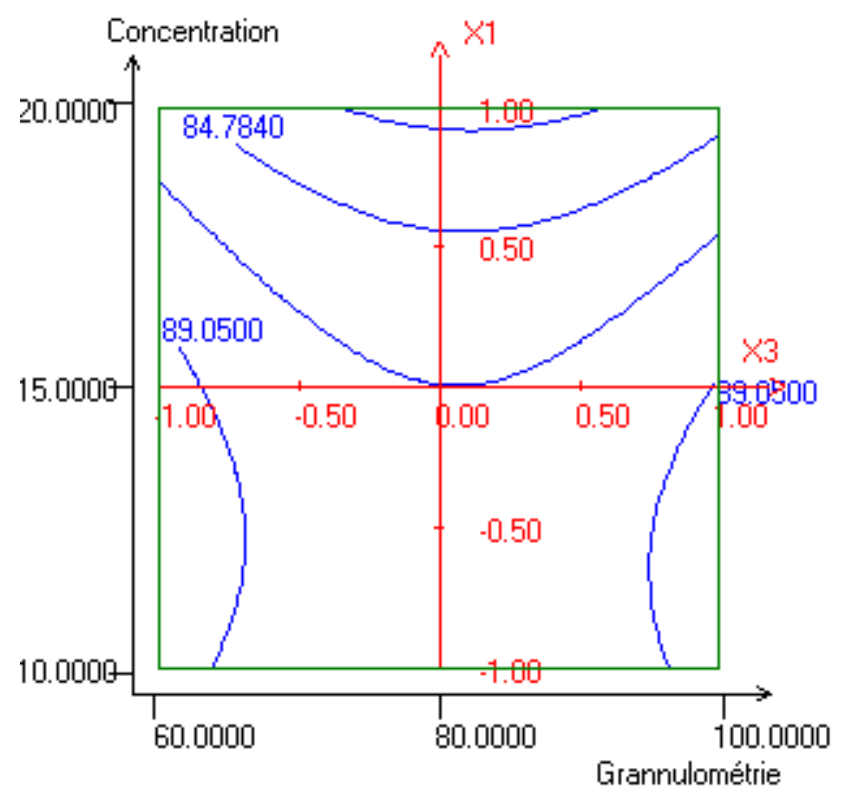

2D
Réponse

95.0080

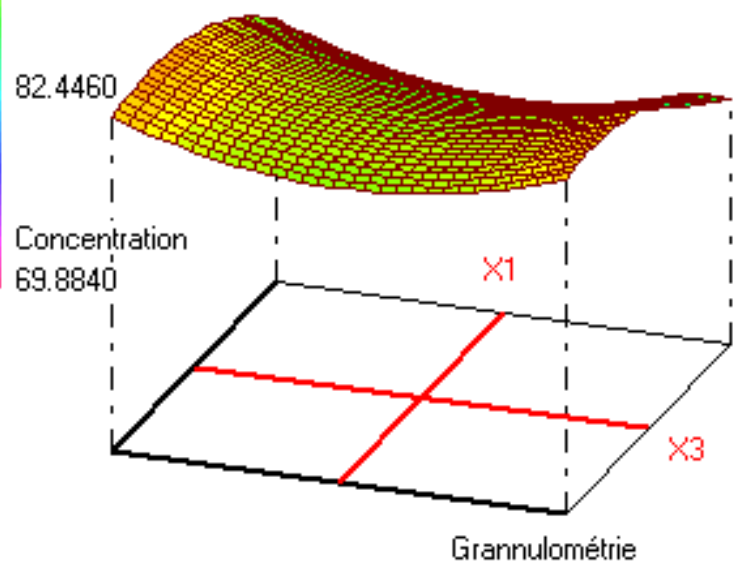

3D

Figure 10: Response surface in 2D and 3D. (Change in the response - Efficiency in the plan: Particle Size, Concentration ;

Factors fixed: - Weight $=0.2 \mathrm{~g}-$ Speed $=1200 \mathrm{rpm}$ ) 


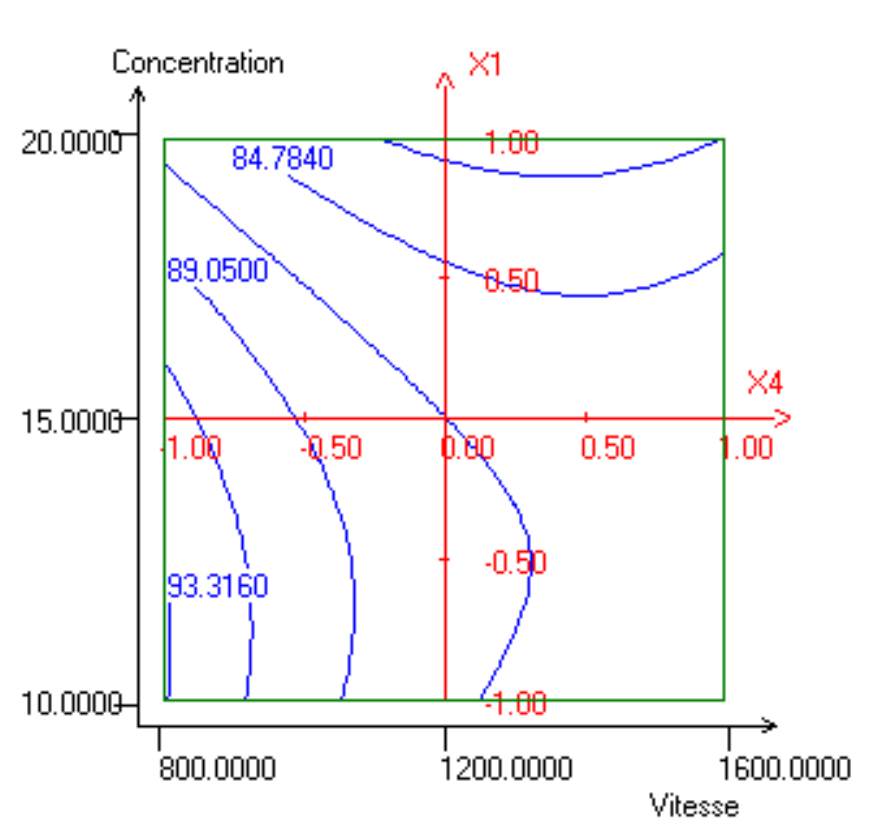

2D
Réponse

95.0080

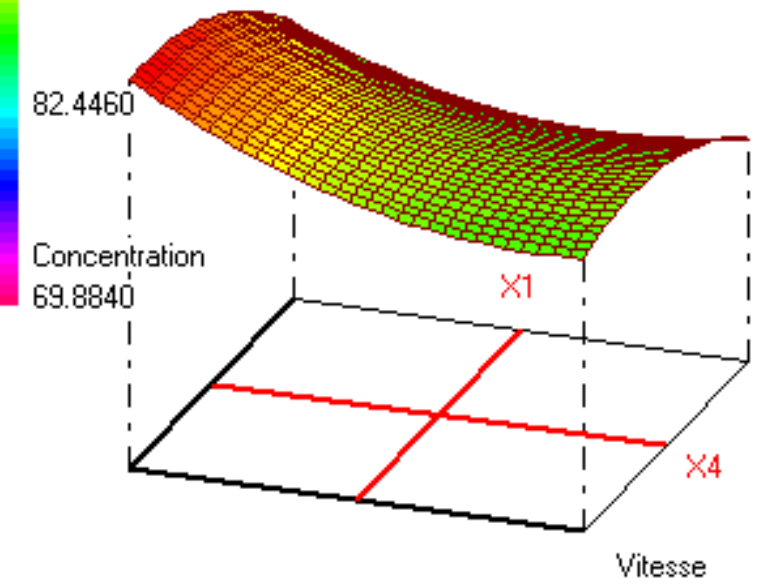

$3 \mathrm{D}$

Figure 11: Response surface in 2D and 3D. (Change in the response - Efficiency in the plan: Speed, Concentration ; Factors fixed: - Weight $=0.2 \mathrm{~g}$ - Particle size $=80$ micrometer $)$

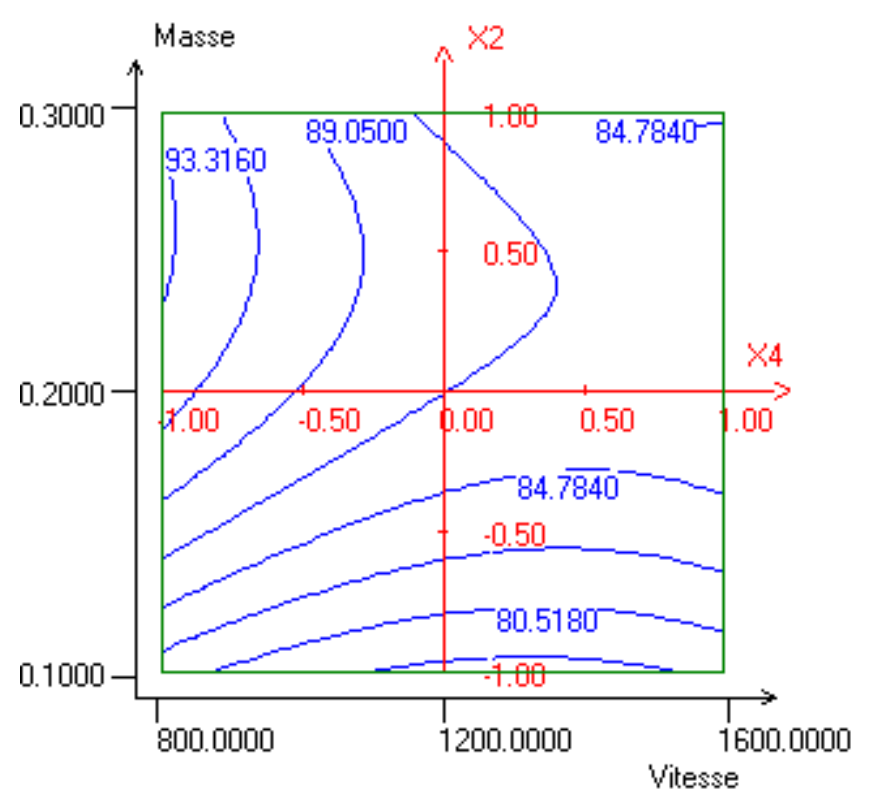

$2 \mathrm{D}$
Réponse

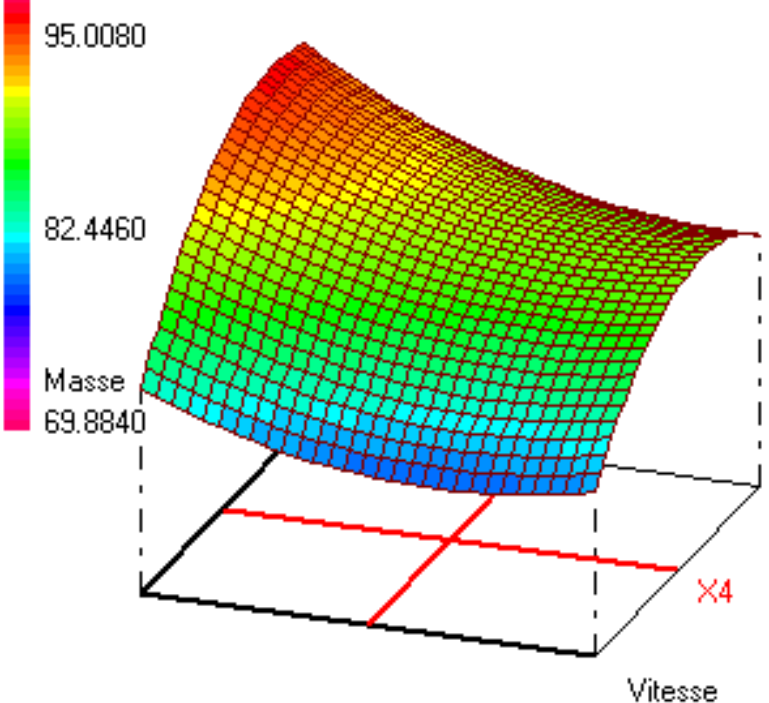

$3 \mathrm{D}$

Figure 12: Response surface in 2D and 3D. (Change in the response - Efficiency in the plan: Speed, Mass ; Factors fixed: Concentration $=15 \mathrm{mg} / \mathrm{l}$ - Particle size $=80$ micrometer)

\section{Conclusion}

From the results above, we can conclude that the sawdust wood used in this study was effective in the adsorption of methylene blue (MB), ranging widely in texture and surface properties. Indeed, the study we have undertaken on performance uses the composite design to 4 factors in the form of a polynomial of the $2^{\text {nd }}$ order. It allowed us to know the influence of all parameters and derive the most influential. The optimization process was carried out and the experimental values for the BM absorption performance were found to be in satisfactory agreement with the values predicted by the models. The optimal condition was obtained using a large adsorbent mass, suggesting that adsorption increases with the surface area of the adsorbent, a fine particle size, low middle stirring speed and low initial concentration of MB. 


\section{References}

1. F. Amegrissi, M. Talbi, M. El Kouali, L. Dahbi, T. Ainane, I. Maghri, J. Mater. Environ. Sci., 3 (2012) 744.

2. T. Ainane, A. Abourriche, M. Kabbaj, M. Elkouali, A. Bennamara, M. Charrouf, M. Talbi, J. Mater. Environ. Sci., 5 (2014) 975.

3. T. Ainane, A. Abourriche, M. Kabbaj, M. Elkouali, A. Bennamara, M. Charrouf, M. Talbi, J. Chem. Pharm. Res., 6 (2014) 599.

4. T. Ainane, F. Khammour, M. Elkouali, M.Talbi, Orien. J. Chem., 30 (2014) 1183.

5. T. Ainane, F. Khammour, O. Belghazi, M. Kabbaj, S. Yousfi, M. Elkouali, M. Talbi, BioTech. Ind. J., 11 (2015) 281.

6. F. Khammour, T. Ainane, A. Kenz, M. Elkouali, M. Talbi, Int. J. Sci. and Res., 4 (2015) 1171.

7. S. Agarwal, I. Tyagi, V.K Gupta, N. Ghasemi, M. Shahivand, M. Ghasemi, J. Mol. Liq., 218 (2016) 208.

8. G. Tian, W. Wang, Y. Kang, A.Wang, J. Taiwan Inst. Chem. Eng., 58 (2016) 417.

9. P.M.K Reddy, P. Verma, C. Subrahmanyam, J. Taiwan Inst. Chem. Eng., 58 (2016) 500.

10. S.M. Miraboutalebi, S.K. Nikouzad, M. Peydayesh, N. Allahgholi, L. Vafajoo, G. McKay, Proc. Saf. Environ. Prot., 106 (2017) 191.

11. M. Rafatullah, O. Sulaiman, R. Hashim, A. Ahmad, J. hazard. Mater., 177 (2010) 70.

12. S. Chatterjee, A. Kumar, S. Basu, S.Dutta, Chem. Eng. J., 181 (2012) 289.

13. M. Chen, W. Ding, J. Wang, G. Diao, Indust. Eng. Chem. Res., 52 (2013) 2403.

14. A. Ahmad, S.H. Mohd-Setapar, C.S. Chuong, A. Khatoon, W.A. Wani, R. Kumar, M. Rafatullah, RSC Advan., 5 (2015) 30801.

15. I. Qadir, R.C. Chhipa, Am. Chem. Sci. J, 6 (2015) 77.

16. C.R. Holkar, A.J. Jadhav, D.V. Pinjari, N.M. Mahamuni, A.B. Pandit, J. Enviro. Manag., 182 (2016) 351.

17. S.A. Ong, L.N. Ho, Y.S. Wong, Desalin. and Wat. Treat., 54 (2015) 557.

18. M.Y. Gaouar, B.Benguella, Indian J. Chem. Techno., 23 (2016) 204.

19. G. Zhou, C. Liu, L. Chu, Y. Tang, S. Luo, Biores. Techno., 219 (2016) 451.

20. Y. Xiao, J.M. Hill, Enviro. Sci. \& Techno., 51 (2017) 4567.

21. J. Hu, W. Deng, D. Chen, ACS Sust. Chem. \& Eng., 5 (2017) 3570.

22. L. Dahbi, "modeling the phenomena of adsorption of pollutants by the sawdust: theoretical and experimental approaches" Thesis, Faculty of Sciences Ben M'sik, Hassan II University Casablanca, Morocco (2010).

23. N. Ertugay, E. Malkoc, Pol J Environ Stud, 23 (2014) 1995.

24. H. Ge, C. Wang, S. Liu, Z. Huang, Biores. Techno., 221 (2016) 419.

25. L.V. Candioti, M.M. De Zan, M.S. Cámara, H.C.Goicoechea, Talanta, 124 (2014) 123.

26. F. Khammour, M. Elkouali, A. Kenz, S. Yousfi, M. Talbi, M. Kabbaj, T. Ainane J. Mater. Environ. Sci.,7 (2016) 1379.

27. C.N. Sakhale, S.N. Waghmare, S.K.Undirwade, V.M. Sonde, M.P. Singh, Proc. Mat. Sci., 6 (2014) 877.

28. A. Asfaram, M. Ghaedi, S. Hajati, M. Rezaeinejad, A. Goudarzi, M.K. Purkait, J. Taiwan Inst. Chem. Eng., 53 (2015) 80.

29. J.N. Sahu, J. Acharya, B.K. Sahoo, B.C. Meikap, Desalin. and Wat. Treat., 57 (2016) 2006.

30. B.K. Sahoo, T.K. Das, A. Gupta, S. De, M. Carsky, B.C. Meikap, S.A J. of Chem. Eng., 23 (2017) 81.

31. B. Sadhukhan, N.K. Mondal, S.Chattoraj, Karbala Inter. J. Mod. Sci., 2 (2016) 145.

32. S. Wang, H. Lin, B. Ru, W. Sun, Y. Wang, Z. Luo, J. Analyt. and App. Pyrol., 108 (2014) 78.

33. X. Gu, X. Ma, L. Li, C. Liu, K. Cheng, Z. Li, J. Analyt. and App. Pyrol., 102 (2013) 16.

34. B. Pizzo, E. Pecoraro, A. Alves, N. Macchioni, J.C. Rodrigues, Talanta, 131 (2015) 14.

\section{(2018); http://www.jmaterenvironsci.com}

